Fetal Diagnosis and Therapy
Fetal Diagn Ther 2017;42:249-256

DOI: $10.1159 / 000457124$
Received: October 27, 2016

Accepted after revision: January 17, 2017 Published online: April 12, 2017

\title{
Intrapartum Ultrasound to Differentiate Flexion and Deflexion in Occipitoposterior Rotation
}

\author{
Federica Bellussi ${ }^{a}$ Tullio Ghi $^{\mathrm{b}}$ Aly Youssef ${ }^{\mathrm{a}}$ Ilaria Cataneo ${ }^{\mathrm{a}}$ Ginevra Salsi $^{\mathrm{a}}$ \\ Giuliana Simonazzi ${ }^{a}$ Gianluigi Pilu $^{a}$ \\ a Department of Obstetrics and Gynecology, University of Bologna, Policlinico S.Orsola-Malpighi, Bologna, and \\ ${ }^{b}$ Department of Obstetrics and Gynecology, University of Parma, Ospedale Maggiore, Parma, Italy
}

\section{Keywords}

Labor · Dystocia · Malpresentation · Malposition ·

Occiput posterior position - Brow presentation - Sinciput

presentation · Ultrasound

\begin{abstract}
Objective: To evaluate the ability of intrapartum ultrasound to differentiate occipitoposterior (OP) rotation with normal flexion of the head from deflexion, to compare the accuracy of ultrasound with the digital examination, and to assess the outcome of labor according to the type of presentation. $\mathbf{P a}$ tients and Methods: A retrospective study of patients with abnormal labor because of either prolongation and/or abnormal cardiotocography and OP rotation who underwent intrapartum sonography. Results: Normal flexion was inferred in 36/42 cases by a longitudinal sonographic view of the fetal face demonstrating the chin approaching the chest. In the remaining 6 , deflexion was diagnosed by visualizing the chin separate and distant from the chest. In 3 of these cases, the orbits were at the same level of the pubis suggesting brow presentation. In the remaining 3 cases, the
\end{abstract}

\section{KARGER}

(C) 2017 S. Karger AG, Basel

E-Mail karger@karger.com

www.karger.com/fdt orbits were above the pubis, and sinciput presentation was inferred. Head deflexion was diagnosed more accurately with ultrasound than clinically and always required a cesarean section versus $36 \%$ of cases with OP flexed presentation $(p=0.0052)$. Conclusions: Fetuses with abnormal labor and OP rotation had deflexed presentations in 14\% of cases and were never delivered vaginally. Sonography was far more accurate than the digital examination.

(c) 2017 S. Karger AG, Basel

\section{Introduction}

The introduction of intrapartum sonography has rekindled the interest of researchers in the mechanics of labor. In particular, several recent studies have addressed the most common malposition, the occipitoposterior (OP) presentation [1-6]. Allowing a precise prospective diagnosis, ultrasound has offered the opportunity to perform prospective studies with the aim to improve the management of these cases [3-5]. Like others, we have previously described the sonographic finding of the fetal

Dr Federica Bellussi

U.O Ostetricia e Medicina Prenatale Azienda Ospedaliero-Universitaria S.Orsola-Malpighi

Via Massarenti 13, IT-40138 Bologna (Italy)

E-Mail bellussi.federica@gmail.com 
Table 1. Maternal, obstetric, and newborn characteristics stratified by type of presentation

\begin{tabular}{|c|c|c|c|c|}
\hline & All cases & Normal flexion & Deflexion & $p$ \\
\hline Cases & 42 & 36 & 6 & - \\
\hline Parity $\geq 1$ & $10(24 \%)$ & $10(28 \%)$ & 0 & $0.3076^{\mathrm{c}}$ \\
\hline Gestational age, weeks & $40(2.3)^{\mathrm{a}}$ & $40.3(2.2)^{\mathrm{a}}$ & $40(2.9)^{\mathrm{a}}$ & $0.3441^{\mathrm{d}}$ \\
\hline Birth weight, $g$ & $3,490(520)^{\mathrm{a}}$ & $3,590(497)^{a}$ & $3,130(322)^{\mathrm{a}}$ & $0.0016^{\mathrm{d}}$ \\
\hline Induction of labor & $22(52 \%)$ & $20(55 \%)$ & $2(33 \%)$ & $0.4004^{\mathrm{c}}$ \\
\hline Epidural analgesia & $24(57 \%)$ & $21(58 \%)$ & $3(50 \%)$ & $1.000^{\mathrm{c}}$ \\
\hline Ultrasound scan performed because of prolonged labor & $27(64 \%)$ & $23(63 \%)$ & $3(50 \%)$ & $0.6580^{\mathrm{c}}$ \\
\hline $\begin{array}{l}\text { Ultrasound scan performed because of abnormal } \\
\text { cardiotocography }\end{array}$ & $15(36 \%)$ & 13 & $3(50 \%)$ & $0.6580^{c}$ \\
\hline Cervical dilatation at the time of ultrasound scan, $\mathrm{cm}$ & $10(8-10)^{\mathrm{b}}$ & $10(8-10)^{\mathrm{b}}$ & $10(8-10)^{\mathrm{b}}$ & $0.5148^{\mathrm{d}}$ \\
\hline Second stage at the time of ultrasound scan & $18 / 46(39 \%)$ & $16 / 36(44 \%)$ & $2 / 6(33 \%)$ & $0.6852^{\mathrm{c}}$ \\
\hline Station at the time of ultrasound scan, $\mathrm{cm}$ & $0(-2 \text { to }+1)^{b}$ & $0(-2 \text { to }+1)^{b}$ & $-1(-2 \text { to } 0)^{\mathrm{b}}$ & $0.0738^{\mathrm{d}}$ \\
\hline Spontaneous vaginal delivery & $12(29 \%)$ & $12(33 \%)$ & 0 & $0.1589^{c}$ \\
\hline Vacuum & $11(26 \%)$ & $11(31 \%)$ & 0 & $0.1724^{\mathrm{c}}$ \\
\hline Cesarean delivery & $19(45 \%)$ & $13(36 \%)$ & $6(100 \%)$ & $0.0052^{\mathrm{c}}$ \\
\hline Umbilical artery $\mathrm{pH}<7.20$ & $9(21 \%)$ & $9(25 \%)$ & 0 & $0.3120^{c}$ \\
\hline
\end{tabular}

${ }^{\mathrm{a}}$ Median (interquartile range); ${ }^{\mathrm{b}}$ median (range); ${ }^{\mathrm{c}}$ Fisher exact test, two-tailed $p ;{ }^{\mathrm{d}}$ Mann-Whitney test.

orbits oriented upward in a transverse view of the maternal abdomen as the hallmark of OP presentation [2, $4-10$ ], a variety of the vertex presentation that may obstruct labor but is compatible with spontaneous vaginal delivery in a substantial proportion of cases $[11,12]$. OP rotation may also occur with deflexed presentations, such as sinciput and brow, that are known to interfere to a greater extent with the descent of the fetal head [13$15]$.

The aim of our study was to evaluate the ability of intrapartum ultrasound to differentiate true OP presentation, in which the head is normally flexed, from OP deflexed presentations, to compare the accuracy of ultrasound with the digital examination, and to assess the outcome of labor according to the type of presentation.

\section{Patients and Methods}

We conducted a retrospective study of patients that were delivered in our hospital in the years 2011-2015 and were seen consecutively by two authors (F.B., G.P.) in advanced labor (cervical dilatation $\geq 8 \mathrm{~cm}$ or in the second stage) because of prolonged labor [16] or abnormal cardiotocography [17] and in which OP rotation was identified sonographically. In each case, a digital exam was initially performed as usual, followed by an ultrasound examination that was conducted with a slight modification of the original approach we have previously described [18]: (1) the orbits were demonstrated in a transverse suprapubic scan; (2) a sagittal view of the face and neck was then obtained; (3) a transperineal scan was eventually performed to visualize the presenting part of the fetal head (Fig. 1). No attempts were made at rotating manually the fetal head, and patients were managed expectantly. When an operative delivery was indicated [19], vacuum was performed only if the fetal station was $\geq+1 \mathrm{~cm}$ and there was no evidence of deflexion [20]. Otherwise, a cesarean section was performed, and the head was delivered first if it could be easily reached. If difficulties were encountered because of either low station or inability to overcome the extension of the head, a reverse breech extraction was performed [21-26].

The relevant clinical data were collected and analyzed. The Mann-Whitney test and the Fisher exact test were used to compare continuous and categorical variables, respectively.

The local Ethics Committee approved the study protocol, and informed consent was obtained from each eligible patient. The study protocol conforms to the ethical guidelines of the "World Medical Association Declaration of Helsinki - Ethical Principles for Medical Research Involving Human Subjects" adopted by the 18th WMA General Assembly, Helsinki, Finland, June 1964, and amended by the 59th WMA General Assembly, Seoul, South Korea, October 2008.

\section{Results}

A total of 42 patients with OP rotation and abnormal labor were retrieved for the analysis. The clinical data are summarized in Table 1 . In 36 cases, normal flexion of the head was inferred by the longitudinal sonographic view of the face demonstrating the chin approaching the chest (Fig. 1). In the remaining 6 cases, deflexion was inferred 


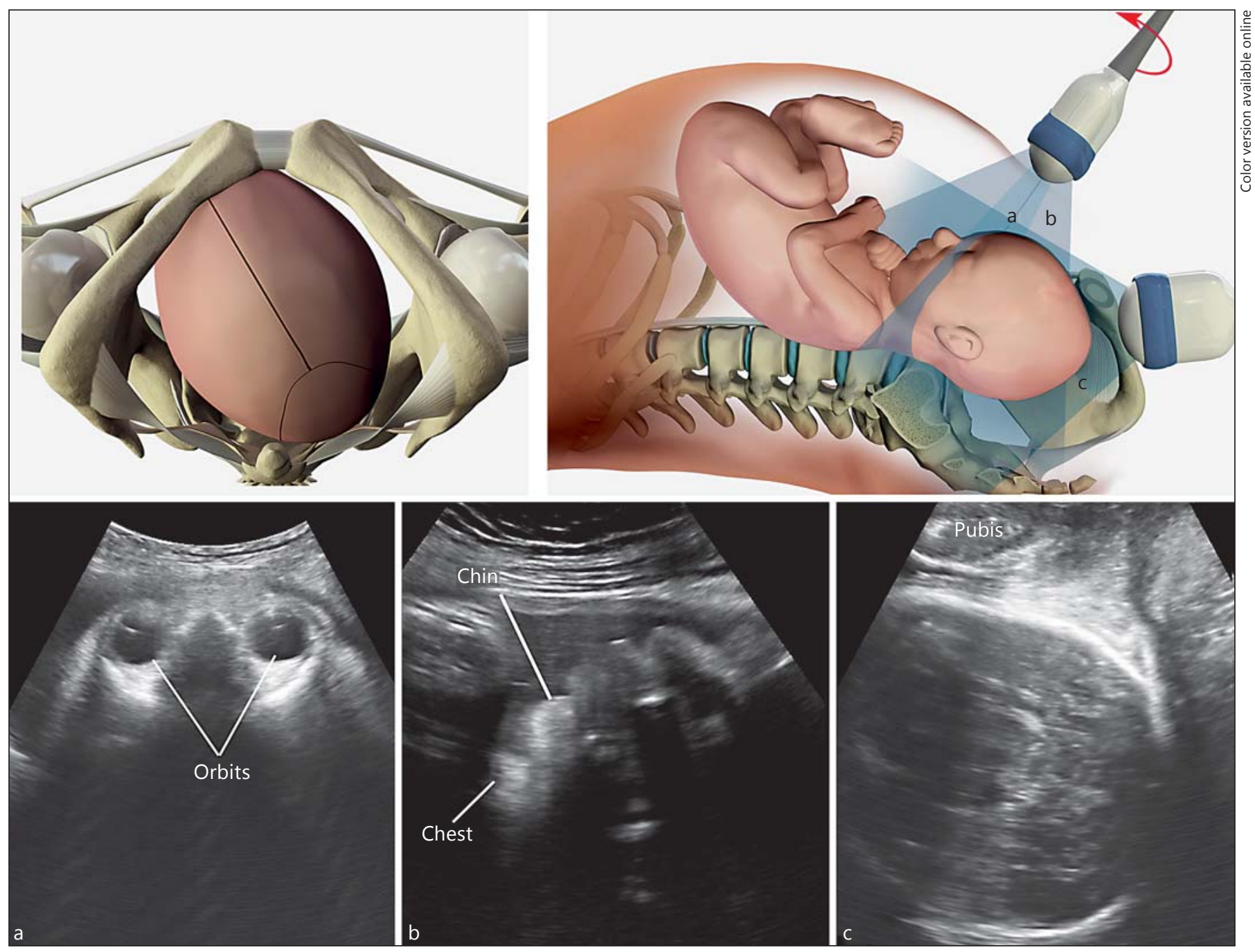

Fig. 1. Occipitoposterior presentation (normal head flexion). Upper left panel: graphic representation of the findings useful for the diagnosis with palpation; the small fontanel and the occipital bone are found in the posterior pelvis. Upper right panel: technique of intrapartum sonography: the transducer is initially positioned on the lower maternal abdomen in a transverse plane (a) to demonstrate the orbits; it is then aligned with the fetal nose and rotated 90 degrees to demonstrate the fetal profile (b); eventually, it is positioned below the pubis at the level of the labia (c). Bottom panel: sonograms corresponding to the three scanning planes demonstrated in the upper right panel. a The orbits oriented upwards indicate that the occiput is posterior. $\mathbf{b}$ Normal flexion of the fetal head is inferred by the sagittal view, demonstrating that the chin points downward towards the fetal chest; the cervical spine is not seen because of the shadowing from the facial bones. $\mathrm{c}$ In the transperineal scan, the fetal orbits are not visible because they are above the pubic symphysis. by visualizing the chin separate and distant from the chest. The deflexion of the head typically facilitated the visualization of the anterior curvature of the cervical spine (Fig. 2 and 3). The transperineal view was also helpful because in 3 cases, it demonstrated the presence of the orbits at the same level as the pubic symphysis, suggesting a brow presentation (see online suppl. video, www. karger.com/doi/10.1159/000457124) [27] (Fig. 2). In the remaining 3 cases, the orbits were seen only above the level of the pubic symphysis, and this suggested a sinciput presentation (Fig. 3). The digital examination performed prior to the ultrasound examination always failed to diagnose deflexion with certainty, although in 2 cases, a suspicion was arisen. Once aware of the sonographic findings, the operators performed a second digital examination and successfully identified findings that had been missed 


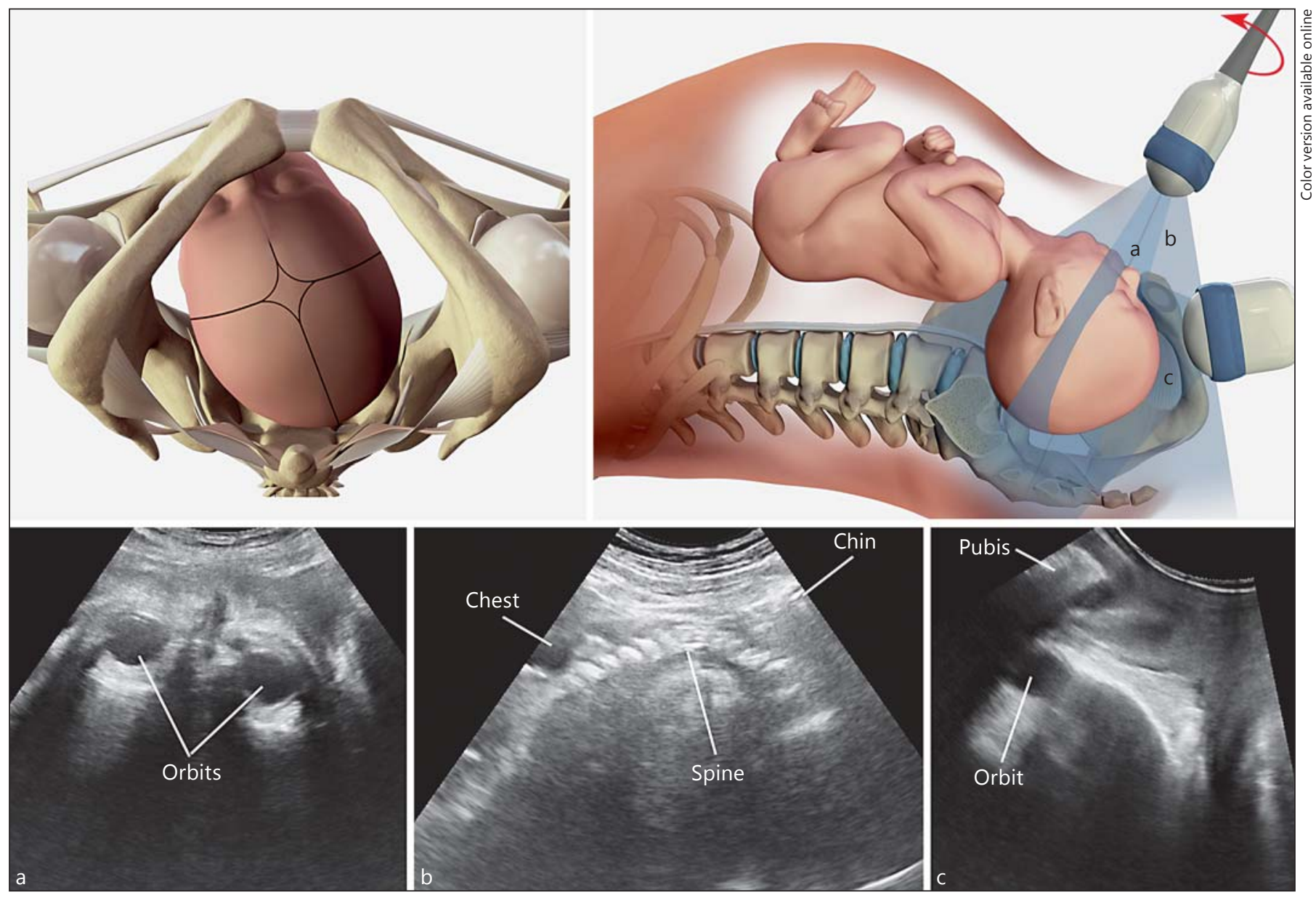

Fig. 2. Brow presentation with posterior occiput. Upper left panel: graphic representation of the findings useful for the diagnosis with palpation; the bregmatic fontanel and the fetal brow can be reached in the anterior pelvis. Upper right panel: the sonographic approach is the same as the one described in Figure 1: the transducer is positioned in the transverse and longitudinal planes of the lower maternal abdomen $(\mathbf{a}, \mathbf{b})$ and below the pubis (c). Bottom panel: so- nograms corresponding to the three scanning planes demonstrated in the upper right panel. a The fetal orbits oriented upwards indicate that the occiput is posterior. $\mathbf{b}$ Deflexion of the fetal head is inferred by the sagittal view: the chin is distant from the fetal chest and the cervical spine is markedly extended. c In the transperineal scan, brow presentation is inferred by the visualization of the fetal orbits at the same level of the pubis. initially (the fetal brow in the superior contour of the head in cases with brow presentation, the large fontanel in the center of the pelvis in cases with sinciput presentation) in $4 / 6$ cases with deflexion. Of the 36 cases with normal flexion, 10 rotated anteriorly and were always delivered vaginally (spontaneously in 9 , with a vacuum extraction in 1). Of the remaining 26 cases with persistent OP, 4 had a spontaneous vaginal delivery, 9 underwent a successful vacuum extraction, and 13 a cesarean section. All cases with deflexion were delivered with a cesarean section, compared with $36 \%$ of those with normal flexion ( $p=$ 0.0052 ). A reverse breech extraction was performed in $3 / 6$ cases with deflexion versus $1 / 13$ cases with normal flexion $(p=0.07)$.

The diagnosis of deflexion was always confirmed at the time of the cesarean section. In 2 of 3 cases with brow presentation, the diagnosis was further attested by the typical position of the caput upon examination of the neonate. Fetuses with normal flexion were significantly larger than those with deflexion. A mild acidemia $(\mathrm{pH}<7.20)$ was diagnosed at birth in 9 cases, but no infant of our series was transferred to the neonatal unit, and all were eventually discharged in good health. 


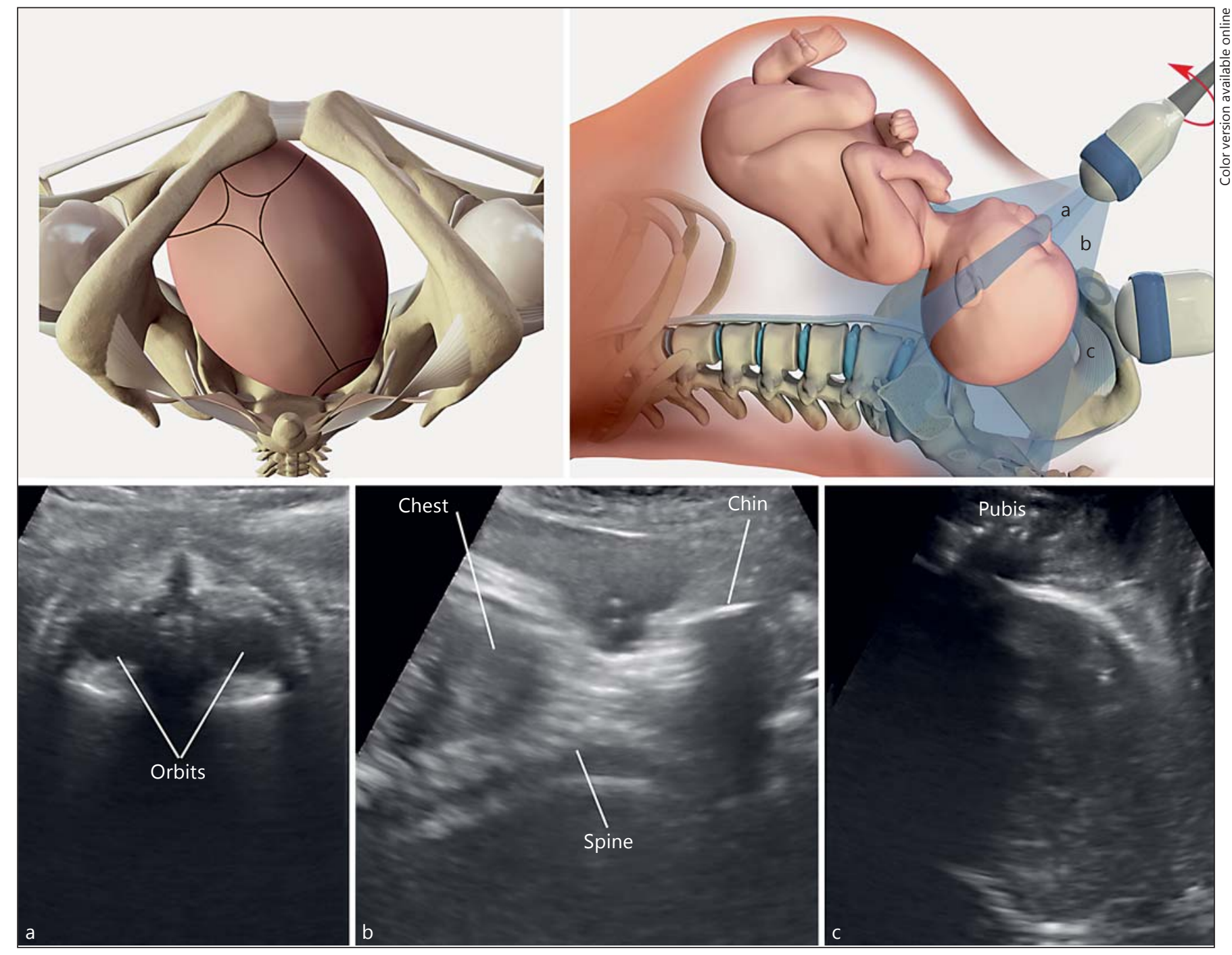

Fig. 3. Sinciput presentation with posterior occiput. Upper left panel: graphic representation of the findings useful for the diagnosis with palpation; both fontanels can be reached and the bregmatic one is in the anterior pelvis. Upper right panel: the sonographic approach is the same as the one described in Figure 1: the transducer is positioned in the transverse and longitudinal planes of the lower maternal abdomen $(\mathbf{a}, \mathbf{b})$ and below the pubis (c). Bottom panel: sonograms corresponding to the three scanning planes demonstrated in the upper right panel. a The fetal orbits. b Deflexion of the fetal head is inferred by the sagittal view: the chin is distant from the fetal chest and the cervical spine is extended. $\mathbf{c}$ In the transperineal scan, the fetal orbits are not visible.

Table 2. Sonographic findings useful for the differential diagnosis of fetuses with sonographic diagnosis of occipitoposterior rotation

\begin{tabular}{lll}
\hline & Suprapubic longitudinal scan & Transperineal scan \\
\hline $\begin{array}{l}\text { Occipitoposterior presentation } \\
\text { (normal flexion) }\end{array}$ & $\begin{array}{ll}\text { Chin tucked into chest } \\
\text { Sinciput presentation }\end{array}$ & Chin separate from chest, cervical spine extended \\
Brow presentation & Chin separate from chest, cervical spine extended & $\begin{array}{l}\text { Orbits above pubic symphysis } \\
\text { Orbits above pubic symphysis } \\
\text { Orbits at the same level or below pubic symphysis }\end{array}$ \\
\hline
\end{tabular}

Intrapartum Sonography of Posterior Occiput Rotation
Fetal Diagn Ther 2017;42:249-256 DOI: $10.1159 / 000457124$ 


\section{Discussion}

\section{Principal Findings}

We have found that in $14 \%$ of patients with abnormal labor and OP rotation, the fetuses have deflexed presentations. Sonographic diagnosis is feasible, and the most useful finding is the demonstration in a sagittal view of the fetal head that the chin is separated from the chest and the cervical spine is curved anteriorly. We have recently described the diagnosis of deflexion of the head in fetuses with anterior occiput by measuring the angle between the spine and the occiput [28]. With OP rotation, the diagnosis is, however, straightforward on a purely qualitative basis (Fig. 1-3). A transperineal scan is also helpful, as visualization of the orbits at the same level or below the maternal pubis indicates a brow presentation [27] (Table 2). Ultrasound performed far better than the clinical assessment. We only suspected the presence of deflexion in 2 cases prior to the ultrasound scan, although a second examination performed in light of the ultrasound findings proved to be more informative. Eventually, none of the patients with deflexion was delivered vaginally, versus $64 \%$ of those with normal flexion.

\section{Implications}

We believe that the main value of our study lies in its perspective. So far, studies on intrapartum ultrasound have considered fetuses with sonographic evidence of OP rotation as a whole group $[1-5,9,29]$. Our data suggest that in these cases, head deflexion may be present and this has a major impact on the outcome of labor. Diagnosis is easy with the sonographic approach we have described and may allow prospective studies to better understand the frequency and clinical significance of this finding as well as the implications for management. We do suggest, however, that there are already a few practical implications worth of note. Recent studies suggest a possible benefit from manual rotation of fetuses with OP presentation $[19,30,31]$, but this maneuver, as well as an operative vaginal delivery, is contraindicated with deflexed presentations [15]. We suggest that prior to attempting such maneuvers, a sagittal sonogram of the fetal head is obtained to exclude deflexion.

Cesarean deliveries in the second stage of labor, with a deeply engaged head, are frequently difficult [26]. In our experience, in half of the cases with deflexion, delivering the head first was hard and a reverse breech extraction was eventually performed. The optimal technique for a difficult cesarean section because of a deeply engaged head is uncertain [26]. In fetuses with OP rotation, we favor reverse breech extraction [21-24] because we have had good results with it. There is little doubt, however, that identification of a deflexed OP fetus with a deeply engaged head suggests that cesarean delivery will be complex, and we believe that in such cases, the presence of an expert obstetric surgeon in the operating theater is advisable.

The end of the spectrum of fetal deflexion is face presentation. During the course of this study, we encountered only one such case with an anterior chin, which we have previously described [32]. In another report, the nose and mouth of the fetus were visualized by transperineal ultrasound [33]. Most likely, in face presentation, the fetal orbits are very deep into the pelvis and even with OP rotation cannot be demonstrated by transabdominal sonography. In our experience, the key sonographic finding of face presentation is the extreme extension of the cervical spine [32]. However, clinical diagnosis in these cases is hardly a problem because recognizing facial parts with palpation is easy.

\section{Strength and Limitations}

The strength of our study is that we have described a systematic approach to the diagnosis of deflexed presentations occurring with a posterior occiput that proved to be simple and effective.

The main weakness of our study is that the physicians managing the labor were the same ones performing the ultrasound examination. One of our most interesting results is indeed that vaginal delivery was never possible when there was sonographic evidence of head deflexion. It is true that all cases were managed expectantly, and cesarean sections were decided only because of arrested or prolonged labor or abnormal cardiotocography. But of course, such decisions suffer from a degree of subjectivity $[17,19]$, and we cannot exclude that the operators were influenced by the sonographic findings. Spontaneous resolution of head deflexion is considered possible [15], although at present, there are no specific figures available.

We remark that our study only included cases with an abnormal course of labor, mostly because of excessive duration. The frequency of deflexion is likely to be lower when the progression is normal. However, although brow and sinciput presentations are commonly reported to be rare events [13-15], the true incidence may be underestimated. The digital examination has already been proven inaccurate for diagnosing fetal position $[7,8,10,34$, 35], and we expect it to be equally imprecise in assessing fetal attitude. Indeed, we always failed to make a certain diagnosis clinically, and it is our experience that at least in our 
department, most practitioners do not report whether the head is deflexed or not when a cesarean section is performed in a fetus with posterior occiput.

\section{Conclusions}

In patients with abnormal labor and a posterior fetal occiput, a deflexed presentation may be present. In these cases, sonography is a powerful enhancement of the traditional digital examination.

\section{Acknowledgments}

Anatomical drawings by Alessandro Meggio - 3DShift srls (3d. ameggio@gmail.com).

\section{Disclosure Statement}

The authors declare that they have no conflicts of interest.

\section{References}

1 Verhoeven CJ, Ruckert ME, Opmeer BC, Pajkrt E, Mol BW: Ultrasonographic fetal head position to predict mode of delivery: a systematic review and bivariate meta-analysis. Ultrasound Obstet Gynecol 2012;40:9-13.

2 Adam G, Sirbu O, Voicu C, Dominic D, Tudorache $\mathrm{S}$, Cernea N: Intrapartum ultrasound assessment of fetal head position, tip the scale: natural or instrumental delivery? Curr Health Sci J 2014;40:18-22.

3 Carseldine WJ, Phipps H, Zawada SF, Campbell NT, Ludlow JP, Krishnan SY, De Vries BS: Does occiput posterior position in the second stage of labour increase the operative delivery rate? Aust NZ J Obstet Gynaecol 2013;53: 265-270.

4 Popowski T, Porcher R, Fort J, Javoise S, Rozenberg P: Influence of ultrasound determination of fetal head position on mode of delivery: a pragmatic randomized trial. Ultrasound Obstet Gynecol 2015;46:520-525.

5 Ramphul M, Ooi PV, Burke G, Kennelly MM, Said SA, Montgomery AA, Murphy DJ: Instrumental delivery and ultrasound: a multicentre randomised controlled trial of ultrasound assessment of the fetal head position versus standard care as an approach to prevent morbidity at instrumental delivery. BJOG 2014;121:1029-1038.

6 Youssef A, Ghi T, Pilu G: How to perform ultrasound in labor: assessment of fetal occiput position. Ultrasound Obstet Gynecol 2013; 41:476-478.

7 Akmal S, Kametas N, Tsoi E, Hargreaves C, Nicolaides $\mathrm{KH}$ : Comparison of transvaginal digital examination with intrapartum sonography to determine fetal head position before instrumental delivery. Ultrasound Obstet Gynecol 2003;21:437-440.

8 Akmal S, Tsoi E, Kametas N, Howard R, Nicolaides KH: Intrapartum sonography to determine fetal head position. J Matern Fetal Neonatal Med 2002;12:172-177.
9 Dupuis O, Ruimark S, Corinne D, Simone T, Andre D, Rene-Charles R: Fetal head position during the second stage of labor: comparison of digital vaginal examination and transabdominal ultrasonographic examination. Eur J Obstet Gynecol Reprod Biol 2005;123:193-197.

10 Souka AP, Haritos T, Basayiannis K, Noikokyri N, Antsaklis A: Intrapartum ultrasound for the examination of the fetal head position in normal and obstructed labor. J Matern Fetal Neonatal Med 2003;13:59-63.

11 Cheng YW, Shaffer BL, Caughey AB: Associated factors and outcomes of persistent occiput posterior position: a retrospective cohort study from 1976 to 2001. J Matern Fetal Neonatal Med 2006;19:563-568.

12 Ponkey SE, Cohen AP, Heffner LJ, Lieberman E: Persistent fetal occiput posterior position: obstetric outcomes. Obstet Gynecol 2003; 101(5 Pt 1):915-920.

13 Bashiri A, Burstein E, Bar-David J, Levy A, Mazor M: Face and brow presentation: independent risk factors. J Matern Fetal Neonatal Med 2008;21:357-360.

14 Gardberg M, Leonova Y, Laakkonen E: Malpresentations - impact on mode of delivery. Acta Obstet Gynecol Scand 2011;90:540-542.

15 Sharshiner R, Silver RM: Management of fetal malpresentation. Clin Obstet Gynecol 2015; 58:246-255.

16 Zhang J, Landy HJ, Branch DW, Burkman R, Haberman S, Gregory KD, Hatjis CG, Ramirez MM, Bailit JL, Gonzalez-Quintero VH, Hibbard JU, Hoffman MK, Kominiarek M, Learman LA, Van Veldhuisen P, Troendle J, Reddy UM; Consortium on Safe Labor: Contemporary patterns of spontaneous labor with normal neonatal outcomes. Obstet Gynecol 2010;116:1281-1287.

17 Macones GA, Hankins GD, Spong CY, Hauth J, Moore T: The 2008 National Institute of Child Health and Human Development workshop report on electronic fetal monitoring: update on definitions, interpretation, and research guidelines. Obstet Gynecol 2008; 112:661-666.
18 Ghi T, Farina A, Pedrazzi A, Rizzo N, Pelusi G, Pilu G: Diagnosis of station and rotation of the fetal head in the second stage of labor with intrapartum translabial ultrasound. Ultrasound Obstet Gynecol 2009;33:331-336.

19 American College of Obstetricians and Gynecologists, Society for Maternal-Fetal Medicine; Caughey AB, Cahill AG, Guise JM, Rouse DJ: Safe prevention of the primary cesarean delivery. Am J Obstet Gynecol 2014; 210:179-193.

20 Committee on Practice Bulletins - Obstetrics: ACOG Practice Bulletin No. 154: Operative vaginal delivery. Obstet Gynecol 2015; 126:e56-e65.

21 Chopra S, Bagga R, Keepanasseril A, Jain V, Kalra J, Suri V: Disengagement of the deeply engaged fetal head during cesarean section in advanced labor: conventional method versus reverse breech extraction. Acta Obstet Gynecol Scand 2009;88:1163-1166.

22 Fasubaa OB, Ezechi OC, Orji EO, Ogunniyi SO, Akindele ST, Loto OM, Okogbo FO: Delivery of the impacted head of the fetus at caesarean section after prolonged obstructed labour: a randomised comparative study of two methods. J Obstet Gynaecol 2002;22:375378.

23 Fong YF, Arulkumaran S: Breech extraction - an alternative method of delivering a deeply engaged head at cesarean section. Int J Gynaecol Obstet 1997;56:183-184.

24 Frass KA, Al Eryani A, Al-Harazi AH: Reverse breech extraction versus head pushing in cesarean section for obstructed labor. A comparative study in Yemen. Saudi Med J 2011; 32:1261-1266.

25 Levy R, Chernomoretz T, Appelman Z, Levin D, Or Y, Hagay ZJ: Head pushing versus reverse breech extraction in cases of impacted fetal head during Cesarean section. Eur J Obstet Gynecol Reprod Biol 2005;121:24-26.
Intrapartum Sonography of Posterior Occiput Rotation
Fetal Diagn Ther 2017;42:249-256 DOI: $10.1159 / 000457124$ 
26 Waterfall H, Grivell RM, Dodd JM: Techniques for assisting difficult delivery at caesarean section. Cochrane Database Syst Rev 2016;1:CD004944.

27 Lau WL, Leung WC, Chin R: Intrapartum translabial ultrasound demonstrating brow presentation during the second stage of labor. Int J Gynaecol Obstet 2009;107:62-63.

28 Ghi T, Bellussi F, Azzarone C, Krsmanovic J, Franchi L, Youssef A, Lenzi J, Fantini MP, Frusca T, Pilu G: The "occiput-spine angle": a new sonographic index of fetal head deflexion during the first stage of labor. Am J Obstet Gynecol 2016;215:84.e1-e7.

29 Chou MR, Kreiser D, Taslimi MM, Druzin ML, El-Sayed YY: Vaginal versus ultrasound examination of fetal occiput position during the second stage of labor. Am J Obstet Gynecol 2004;191:521-524.
30 Le Ray C, Serres P, Schmitz T, Cabrol D, Goffinet F: Manual rotation in occiput posterior or transverse positions: risk factors and consequences on the cesarean delivery rate. Obstet Gynecol 2007;110:873-879.

31 Shaffer BL, Cheng YW, Vargas JE, Laros RK Jr, Caughey AB: Manual rotation of the fetal occiput: predictors of success and delivery. Am J Obstet Gynecol 2006;194:e7-e9.

32 Ghi T, Maroni E, Youssef A, Cariello L, Salsi G, Arcangeli T, Frasca C, Rizzo N, Pilu G: Intrapartum three-dimensional ultrasonographic imaging of face presentations: report of two cases. Ultrasound Obstet Gynecol 2012;40:117-118.
33 Eggebo TM, Eymundsdottir AE, Ostborg TB: Face presentation and persistent deep mentum transverse position diagnosed with three-dimensional ultrasound. Ultrasound Obstet Gynecol 2015;45:490-491.

34 Sherer DM, Miodovnik M, Bradley KS, Langer O: Intrapartum fetal head position II: comparison between transvaginal digital examination and transabdominal ultrasound assessment during the second stage of labor. Ultrasound Obstet Gynecol 2002;19:264-268.

35 Sherer DM, Miodovnik M, Bradley KS, Langer O: Intrapartum fetal head position I: comparison between transvaginal digital examination and transabdominal ultrasound assessment during the active stage of labor. Ultrasound Obstet Gynecol 2002;19:258-263. 